\title{
Volumetric Capnography to Assess Functional Respiratory Disturbances in Patients with Bronchia Asthma
}

\author{
DOI: 10.17691/stm2017.9.3.13
}

Received November 14, 2016

S.V. Subbotin, PhD Student, Department of Therapy with a Family Medicine Course, Faculty

of Continuing Professional Education;

I.B. Ponomaryova, MD, PhD, Teaching Assistant, Department of Therapy with a Family Medicine Course,

Faculty of Continuing Professional Education;

Yu.Yu. Byalovskiy, MD, DSc, Professor, Head of Pathophysiology Department;

V.N. Abrosimov, MD, DSc, Professor, Head of Department of Therapy with a Family Medicine Course, Faculty of Continuing Professional Education

Ryazan State Medical University named after Academician I.P. Pavlov, Vysokovoltnaya St., 9, Ryazan, 390026, Russian Federation

Spirometry, which implies carrying out forced expiration procedure, frequently, presents a problem, especially in patients with severe asthma, providing no idea of small airways condition. Volumetric capnography has no limitations typical for spirometry.

The aim of the investigation was to study the capabilities of volumetric capnography to determine functional respiratory disturbances in patients with bronchial asthma.

Materials and Methods. 171 male and female patients were examined, including 46 patients with severe bronchial asthma and 42 patients with moderate bronchial asthma. A control group consisted of 83 apparently healthy volunteers. All the subjects under study underwent a clinical examination. In addition, their spirometry and volumetric capnography findings were evaluated using an ultrasound computed spirograph SpiroScout (Ganshorn, Germany) capable of volumetric capnography. In addition, body plethysmography was carried out.

Results. Volumetric capnography revealed the following changes in bronchial asthma patients compared to the controls: phase III inclination angle increase $(\mathrm{g} / \mathrm{mol} \cdot \mathrm{L})$, which indicates heterogeneity of lung periphery ventilation and perfusion due to small airways pathology, and an emphysema index characterizing pulmonary hyperinflation. Phase III inclination angle alterations were significant in different bronchial asthma severity degrees. A post-bronchodilator test with Salbutamol $(400 \mu \mathrm{g})$ in the patients with bronchial asthma were found to show an increase in anatomical dead space $(\mathrm{ml})$ and phase II inclination angle decrease $(\mathrm{g} / \mathrm{mol} \cdot \mathrm{L})$. Phase III inclination angle and an emphysema index of volumetric capnography demonstrated a correlation relationship with spirometry and body plethysmography parameters.

Conclusion. Volumetric capnography extends the concept of the nature and degree of an impaired respiratory function in bronchial asthma. It enables to assess small airways function and determine the presence and extent of lung hyperinflation in patients with bronchial asthma.

Key words: bronchial asthma; volumetric capnography; spirometry; body plethysmography; emphysema index; small airways.

A combined examination of patients suffering from bronchial asthma (BA) involves the evaluation of complaints, anamnestic data, clinical evidence and respiratory function. Respiratory function study is a required technique to analyze ventilatory disturbances, which determine clinical presentation characteristics and the severity degree $[1,2]$. Currently, it is spirometry that is of higher priority when assessing respiratory disturbances in such patients, since spirometry includes a bronchodilatory test.

Spirometry is the most common technique for functional diagnostics and monitoring in obstructive respiratory failures in BA patients $[1,3,4]$. The technique has no absolute contraindications; however, carrying out forced expiration procedure, frequently, presents a problem, especially in patients with severe BA [5-7]. Small airways (SAW) dysfunction has been found to be of great importance in airway resistance formation in BA [8-10]. A severe BA phenotype characterized by a high risk of fatality, as well as a phenotype with persisting bronchial obstruction have been suggested to be associated with marked SAW inflammation, obstruction and impaired relationship with alveoli resulting in respiratory disturbances [11-13]. In BA pathogenesis, an emphasis is laid on lung hyperinflation, especially in exacerbations and during asthma attacks. Spirometry fails to verify SAW hyperinflation and obstructive alterations. It raises the necessity to study and introduce other respiratory function assessment tools.

Currently, body plethysmography is used for these

For contacts: Sergei V. Subbotin, e-mail: subbotinsv.89@mail.ru 
purposes [14]. Capnography is an integral part of respiratory failure diagnostics, it being used to measure carbon dioxide $\left(\mathrm{CO}_{2}\right)$ level in expired air. When studying a capnographic curve, in particular, the inclination angle alteration of an ascending part of capnogram (Van Merten index: $\mathrm{RCO}_{2}$ ), one can reveal obstructive respiratory disease [15].

One of promising techniques of functional diagnostics of respiratory disorders is volumetric capnography [15, 16]. In contrast to a traditional technique, it estimates $\mathrm{CO}_{2}$ changes referring to respiratory volume [15] followed by the calculation of a number of parameters: dead space, phase II and III inclination angles, emphysema index [17]. There are several devices used to record volumetric capnograms, among them there is an ultrasound computed spirograph SpiroScout (Ganshorn, Germany) with volumetric capnography function.

Each phase of a volumetric capnogram has its physiological significance (Figure 1).

Phase I shows $\mathrm{CO}_{2}$ concentration exhaled from upper airways (i.e. carbon dioxide of anatomical dead space); phase I increase indicates the growth of anatomical dead space ventilation $\left(V D_{a w}\right)$.

Phase II presents $\mathrm{CO}_{2}$ from airways with gas impurities from alveoli, and indicates perfusion alterations; phase II decrease can be indicative of perfusion reduction.

Phase III, or alveolar plateau, presents data on $\mathrm{CO}_{2}$ released from alveoli, and characterizes gas distribution, the lung periphery ventilation and perfusion [18], which in its turn indicates SAW condition and pulmonary hyperinflation [18-21].

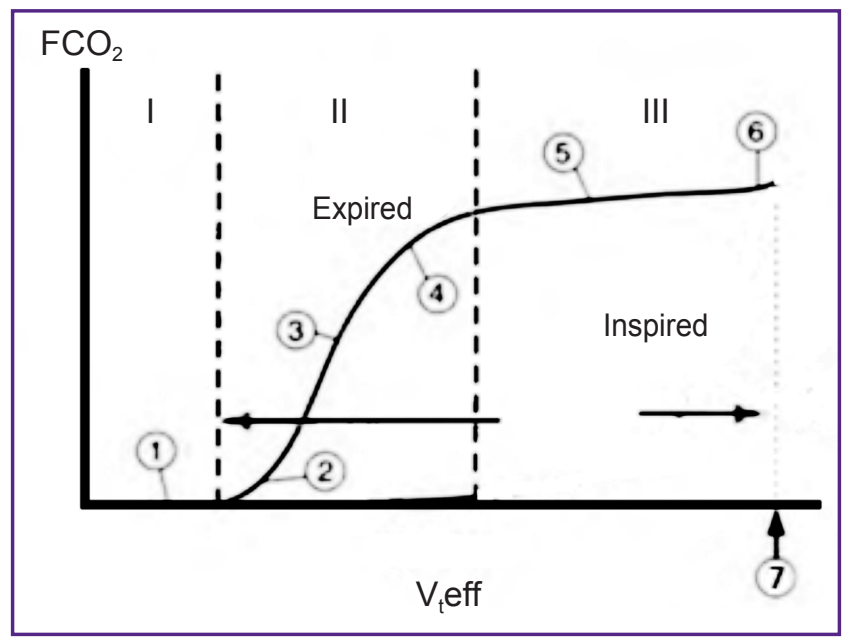

Figure 1. Volumetric capnogram [17]:

I-III: capnogram phases; (1) dead space volume; (2) transition of phase I to phase II; (3) phase II inclination; (4) alpha angle (transition of phase II to phase III); (5) phase III inclination; (6) expiration end; (7) released $\mathrm{CO}_{2}$ volume (area between the curves); $\mathrm{FCO}_{2}$ : fractional carbon dioxide in the expired air; $V_{t}$ eff: effective respiratory volume
The calculated parameters of volumetric capnography will enable to determine the dead space volume, respiratory volume, the amount of released $\mathrm{CO}_{2}$, as well as assess the lung periphery condition (ventilationperfusion ratio inhomogeneity). At the same time, the technique enables to estimate the presence of hyperinflation (emphysema) in patients with obstructive respiratory diseases. The use of a pulmonary functional test ("emphysema test") that helps determine an integral parameter - slope of the regression line of mixed air index - is original $[18,22]$. In lung emphysema, mixed air volume containing from 25 to $50 \%$ maximum $\mathrm{CO}_{2}$ concentration $\left(\mathrm{Vm}_{25-50}\right)$ undergoes the greatest changes. The parameter is called an 'emphysema index'. It depends on inspiratory volume ( $\left.\mathrm{VT}_{\text {ins }}\right)$, therefore, $\mathrm{Vm}_{25-50}$ to $\mathrm{VT}_{\text {ins }}$ ratio is used to diagnose emphysema.

Among the advantages of volumetric capnography, special mention should be made of the informativity, noninvasiveness, easiness of use, as well as no need to perform forced respiration that is significant for patients with severe BA. The device to perform the procedure is portable and low cost.

In literature there are enough reports of the studies demonstrating the capabilities of clinical use of volumetric capnography in anesthesiology and intensive care [21, $23,24-27$ ] to diagnose thromboembolia of pulmonary artery [28-32] and respiratory distress syndrome [33, 34], and there are just a few reports devoted to the assessment of volumetric capnography variations in patients with BA [19, 35] and COPD [20, 36-38], it causing the necessity of further studies of the method.

The aim of the investigation was to study the capabilities of volumetric capnography to determine functional respiratory disturbances in patients with bronchial asthma.

Materials and Methods. It was a cohort and noninterventional study. 88 male and female patients were examined. Among them there were 46 patients with severe BA and 42 patients with moderate BA, with a different extent of disease control. A control group involved 83 apparently healthy volunteers. BA diagnosis was made according to GINA 2015 criteria [1].

BA patients and the controls were similar in age, sex and anthropometrical data (Table 1).

The study complies with the Declaration of Helsinki (the Declaration was passed in June 1964, Helsinki, Finland, and revised in October 2000, Edinburgh, Scotland) and was performed following approval by the Ethic Committee of Ryazan State Medical University named after Academician I.P. Pavlov. Written informed consent was obtained from every patient.

To record volumetric capnography and spirometry findings, we used an ultrasound computed spirograph SpiroScout (Ganshorn, Germany) with volumetric capnography function (Figure 2). Spirometry was performed in accordance with ATS/ERS standards. Body plethysmography was carried out using a body plethysmograph Q-box (COSMED, Italy). 
Anthropometric data of patients with bronchial asthma and a control group $(\mathrm{M} \pm \sigma)$

\begin{tabular}{|lcc|}
\hline \multicolumn{1}{|c}{ Parameters } & $\begin{array}{c}\text { Bronchial asthma } \\
\text { group ( } \mathrm{n}=88)\end{array}$ & $\begin{array}{c}\text { Control group } \\
(\mathrm{n}=83)\end{array}$ \\
\hline Age (years) & $59.5 \pm 1.6$ & $57.4 \pm 1.6$ \\
\hline Sex (male/female) & $28 / 60$ & $20 / 63$ \\
\hline Height (cm) & $165.3 \pm 8.4$ & $165.5 \pm 0.9$ \\
\hline Mass $(\mathrm{kg})$ & $82.2 \pm 2.1$ & $78.2 \pm 1.6$ \\
\hline Body mass index & $30.20 \pm 5.50$ & $28.53 \pm 0.54$ \\
\hline
\end{tabular}

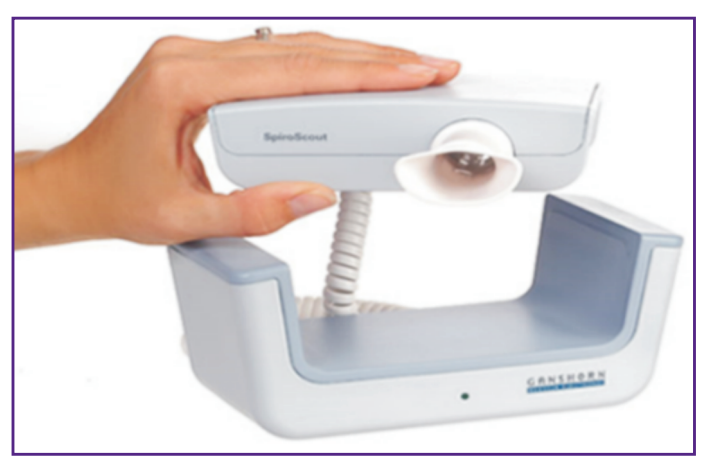

Figure 2. SpiroScout spirograph with volumetric capnography function (Ganshorn, Germany)
Functional respiratory study included the assessment of spirography and body plethysmograph findings, which were compared with those of volumetric capnography. The respiratory parameters of BA patients were recorded twice: before and $20 \mathrm{~min}$ after the inhalation of a short-acting bronchodilator (Salbutamol, $400 \mu \mathrm{g}$ ).

Body plethysmography was performed in 32 controls and 30 patients with BA. All BA patients used no long-acting bronchial spasmolytics $12 \mathrm{~h}$ before the examination and short-acting bronchial spasmolytics $6 \mathrm{~h}$ before the examination.

The findings were statistically processed using a software package Statistica 10.0 (StatSoft Inc., USA). The results are presented as a mean \pm standard deviation for Gaussian samples, and as a median with 25$75 \%$ interquartile range for samples different to Gaussian samples. The differences were considered significant if $p<0.05$, Spearman's rank correlation coefficient being used.

Results and Discussion. Table 2 shows the findings of spirometry, body plethysmography and volumetric capnography.

According to spirometry, BA patients compared to a control group were found to have a significant decrease of respiratory function parameters: forced expiratory volume per during the first second (FEV1, \% of reference value), forced vital lung capacity (FVLC, \% of reference value), modified Tiffeneau index (Gaenslar index) (FEV1/ FVLC, \%). Moreover, the patients with different severity

Table 2
Spirometry, volumetric capnography and body plethysmography findings in patients with bronchial asthma and a control group

\begin{tabular}{|c|c|c|}
\hline Parameter & Bronchial asthma group ( $n=88)$ & Control group ( $n=83$ ) \\
\hline \multicolumn{3}{|c|}{ Spirometry } \\
\hline FEV1 (\% of reference value) & $59.50 \pm 1.72^{*}$ & $98.98 \pm 1.26$ \\
\hline FVLC ( $\%$ of reference value) & $74.91 \pm 2.08^{*}$ & $102.86 \pm 1.29$ \\
\hline FEV1/FVLC (\%) & $76.22 \pm 2.45^{*}$ & $109.67 \pm 2.47$ \\
\hline \multicolumn{3}{|c|}{ Body plethysmography } \\
\hline & Bronchial asthma group $(n=30)$ & Control group ( $n=32$ ) \\
\hline PRV (\% of reference value) & $166.5(136.5 ; 291)^{*}$ & $110.5 \pm 6.22$ \\
\hline PRV/TLC (\%) & $65.75 \pm 6.4^{*}$ & $58.75 \pm 4.82$ \\
\hline$R_{\mathrm{aw}}(\mathrm{kPa} / \mathrm{L})$ & $200.3 \pm 46.73^{*}$ & $83.58 \pm 8.95$ \\
\hline \multicolumn{3}{|c|}{ Volumetric capnography } \\
\hline$V D_{\text {Fowler }}(\mathrm{ml})$ & $126(106 ; 154)^{*}$ & $154(126 ; 189)$ \\
\hline $\mathrm{dMM} / \mathrm{dV} 2(\mathrm{~g} / \mathrm{mol} \cdot \mathrm{L})$ & $2.78(2.1 ; 3.44)$ & $2.55(1.9 ; 3.31)$ \\
\hline $\mathrm{dMM} / \mathrm{dV} 3(\mathrm{~g} / \mathrm{mol} \cdot \mathrm{L})$ & $0.26(0.19 ; 0.36)^{*}$ & $0.19(0.11 ; 0.26)$ \\
\hline Alpha s2s3 (degrees) & $127(117 ; 135)^{*}$ & $124(119 ; 128)$ \\
\hline dMMmax (g/mol) & $0.42 \pm 0.01^{*}$ & $0.37 \pm 0.01$ \\
\hline $\mathrm{Vm}_{25-50} \mathrm{NT}_{\text {ins }}$ & $35.64(12.8 ; 75.9)^{*}$ & $18.43 \pm 1.47$ \\
\hline
\end{tabular}

* Significant difference with controls, $p<0.05$. FEV1: forced expiratory volume during the first second; FVLC: forced vital lung capacity; FEV1/FVLC: Gaenslar index; PRV: pulmonary residual volume; PRV/TLC: the ratio of pulmonary residual volume to total lung capacity; $\mathrm{R}_{\mathrm{aw}}(\mathrm{kPa} \mathrm{s} / \mathrm{L})$ : bronchial resistance index; $\mathrm{VD}_{\text {Fowler }}$ : dead space volume according to Fowler; $\mathrm{VT}_{\text {ins }}$ : respiratory volume; $\mathrm{dMM} / \mathrm{dV} 2$ : phase II inclination; dMM/dV3: phase III inclination; Alpha s2s3: alpha angle between phase II and III; $\mathrm{dMM}_{\max }$ : maximum molar mass of total $\mathrm{CO}_{2}$ released during the expiration related to the volume; $\mathrm{Vm}_{25-50} / \mathrm{VT}_{\text {ins }}$ : emphysema index.

degrees demonstrated the significant difference in FEV1 values ( $\%$ of reference value) between themselves and compared to a control group: $46.40 \pm 10.25$ in severe $\mathrm{BA}, 68.47 \pm 0.92$ in moderate $\mathrm{BA}$, and $98.98 \pm 1.26$ in the controls. FEV1 increased significantly in BA patients after bronchial spasmolytic inhalation (Table 3). 
Table 3

Pre- and post-bronchodilatory indices of spirometry and volumetric capnography in patients with bronchial asthma

\begin{tabular}{|c|c|c|}
\hline Parameter & Pre-bronchodilation $(n=88)$ & Post-bronchodilation $(n=88)$ \\
\hline \multicolumn{3}{|c|}{ Spirometry } \\
\hline FEV1 (\% of reference value) & $59.50 \pm 1.72^{*}$ & $67.31 \pm 1.75$ \\
\hline FVLC (\% of reference value) & $74.91 \pm 2.08^{*}$ & $81.28 \pm 1.89$ \\
\hline FEV1/FVLC (\%) & $76.22 \pm 2.45$ & $77.82 \pm 1.79$ \\
\hline \multicolumn{3}{|c|}{ Volumetric capnography } \\
\hline $\mathrm{VD}_{\text {Fowler }}(\mathrm{ml})$ & $126(106 ; 154)$ & $131(112 ; 158)$ \\
\hline $\mathrm{dMM} / \mathrm{dV} 2(\mathrm{~g} / \mathrm{mol} \cdot \mathrm{L})$ & $2.78(2.1 ; 3.44)^{*}$ & $2.38(1.73 ; 2.85)$ \\
\hline $\mathrm{dMM} / \mathrm{dV} 3(\mathrm{~g} / \mathrm{mol} \cdot \mathrm{L})$ & $0.26(0.19 ; 0.36)$ & $0.24 \pm 0.01$ \\
\hline Alpha s2s3 (degrees) & $127(117 ; 135)$ & $128.39 \pm 0.93$ \\
\hline $\mathrm{dMM}_{\max }(\mathrm{g} / \mathrm{mol} \cdot \mathrm{L})$ & $0.42 \pm 0.01^{*}$ & $0.37 \pm 0.01$ \\
\hline $\mathrm{Vm}_{25-50} \mathrm{NT}_{\text {ins }}$ & $35.64(12.8 ; 75.9)^{*}$ & $25.2(11.09 ; 57.9)$ \\
\hline
\end{tabular}

* Significant difference of values with post-bronchodilatation indices. FEV1: forced expiratory volume during the first second; FVLC: forced vital lung capacity; FEV1/FVLC: Gaenslar index; dMM/dV2: phase II inclination; dMM/dV3: phase III inclination; Alpha s2s3: alpha angle between phase II and III; dMMmax: maximum molar mass of total $\mathrm{CO}_{2}$ released during the expiration related to the volume; $\mathrm{Vm}_{25-50} / \mathrm{VT}_{\text {ins }}$ : emphysema index

According to body plethysmography, compared to the controls, BA patients were found to have an increase in pulmonary residual volume (PRV) (as \% of reference value) and the ratio of pulmonary residual volume to total lung capacity (PRV/TLC) (as \%) that was caused by an air cushion effect. In addition, $\mathrm{R}_{\mathrm{aw}}(\mathrm{kPa} \mathrm{s} / \mathrm{L})$ - airways resistance index - also increased in BA patients compared to the controls due to bronchial obstruction (See Table 2).

The analysis of volumetric capnography indices showed the anatomical dead space volume $\left(\mathrm{VD}_{\text {Fowler }}\right)$ in a BA group to be significantly lower than in a control group due to bronchial obstruction.

No reliable differences of phase II inclination angle values $(\mathrm{dMM} / \mathrm{dV} 2)$ were found in $B A$ patients and the controls. However, its decrease in BA patients after taking Salbutamol indicates indirectly the change of dead space amount in response to bronchodilation (Table 3). The findings are consistent with those by Almeida et al. [19], who studied volumetric capnography in children with controlled persisting BA. The correlation dependence of $\mathrm{dMM} / \mathrm{dV} 2$ with body plethysmography indices PRV ( $r=0.68)$ and $R_{a w}(r=0.74)$ was found.

Phase III inclination angle (dMM/dV3) characterizes the condition of the lung periphery ventilation and perfusion [18]. In healthy subjects with minimal ventilation inhomogenuity this curve phase is flat. In patients with SAW pathology, phase III has a slope proportional to ventilation inhomogenuity. $\mathrm{dMM} / \mathrm{dV} 3$ value was significantly higher in BA patients compared to the controls that is consistent with the data obtained by Almeida [19]. Romero et al. [37] when estimating the capabilities of the method in examining patients with COPD also found the index increase. Thus, phase III inclination angle change in BA patients compared to the controls indicates ventilation inhomogenuity due to distal airway pathology (Figure 3). In addition, the parameter values differed significantly in patients with moderate $(0.25 \pm 0.02)$ and severe BA (0.32 \pm 0.004$)$. The assessment of $\mathrm{dMM} / \mathrm{dV} 3$ before and after Sulbutamol showed no reliable difference that can be due to irreversible changes of distal airways [17]. The parameter had correlation dependence with FEV1 of spirometry ( $r=-0.47$ ) and $R_{a w}$ of body plethysmography $(r=0.55)$.

An inclination angle between phases II and III (Alpha s2s3) was significantly higher in BA patients compared to the controls due to irregular "emptying" of alveoli breathing out in bronchial obstruction [18]. There was found the correlation of the parameter with FEV1 of spirometry ( $r=-0.36)$ and PRV/TLC of body plethysmography ( $r=-0.32)$.

Maximal molar mass of total $\mathrm{CO}_{2}\left(\mathrm{dMM}_{\max }\right)$ released during the expiration, and related with the volume was significantly higher in BA patients compared to the controls; after bronchial spasmolytic inhalation the parameter reduced that can be due to expiratory volume change.

The lung hyperinflation in the subjects under study was determined using an emphysema test (Figure 4). BA patients had significantly higher $\mathrm{Vm}_{25-50} / \mathrm{VT}_{\text {ins }}$ index compared to a control group. $\mathrm{Vm}_{25-50} / \mathrm{VT}_{\text {ins }}$ correlated 


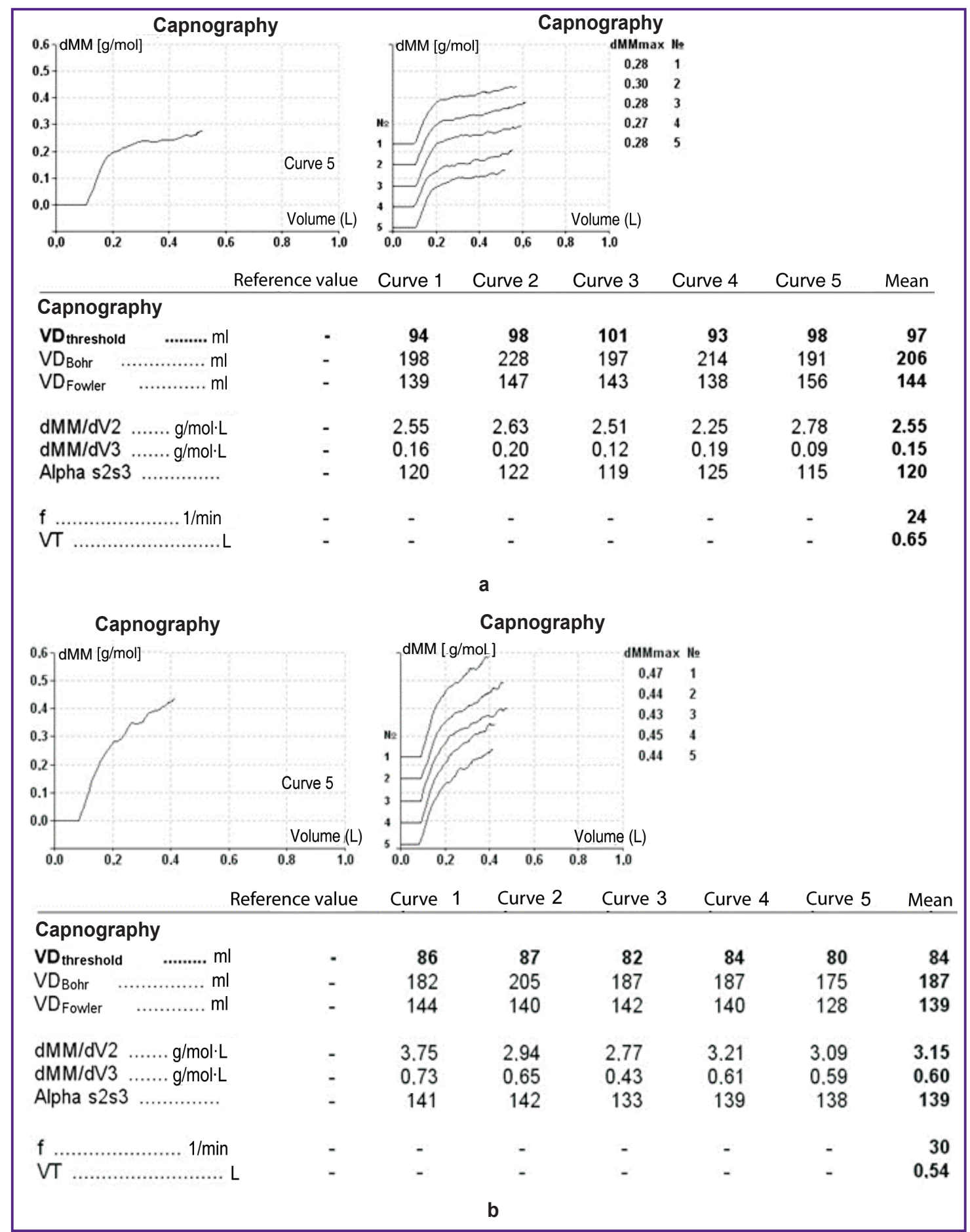

Figure 3. Volumetric capnogram: normal (a) and in respiratory obstruction (b):

$\mathrm{VD}_{\text {threshold }}$ : dead space determined by a threshold method; $\mathrm{VD}_{\text {Bohr }}$ : dead space determined according to Bohr technique; $V D_{\text {Fowler }}$ dead space determined according to Fowler technique; dMM/dV2: phase II inclination; dMM/dV3: phase III inclination; Alpha s2s3: alpha angle (transition of phase II to phase III); f: respiration rate; VT: respiratory volume; $\mathrm{dMM}_{\max }$ : maximum molar mass of total $\mathrm{CO}_{2}$ released during the expiration related to the volume

to FEV1 of spirometry ( $r=-0.32)$ and to PRV of body plethysmography $(r=0.50)$.

Thus, the analysis of volumetric capnography findings showed the anatomic dead space volume $\left(\mathrm{VD}_{\text {Fowler }}\right)$ in a BA group was significantly lower than in the control group. BA patients after Salbutamol taking had a decrease of phase II inclination angle (dMM/dV2), an increase in phase III inclination angle (dMM/dV3), and 

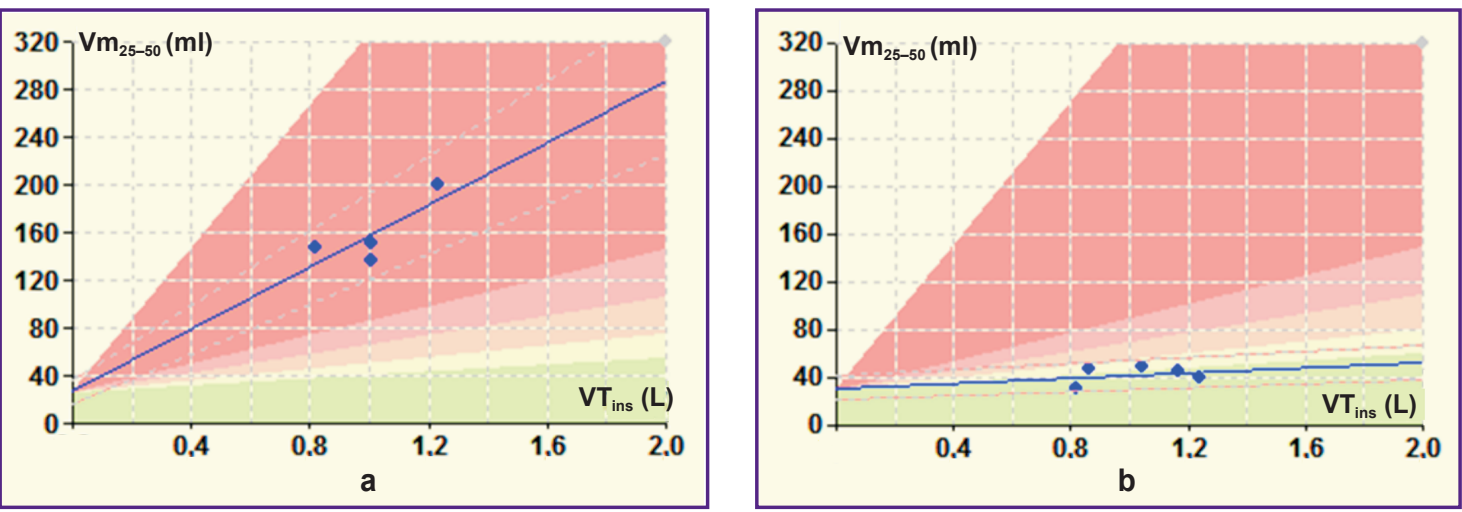

Figure 4. Emphysema test:

(a) in a patient with lung hyperinflation ( $\left.\mathrm{Vm}_{25-50} / \mathrm{VT}_{\text {ins }}-130.43\right)$; (b) in a control patient $\left(\mathrm{Vm}_{25-50} \mathrm{NT}_{\text {ins }}-10.62\right)$

inclination angle between phase II and III (Alpha s2s3) and emphysema index $\left(\mathrm{Vm}_{25-50} / \mathrm{VT}_{\text {ins }}\right)$ compared to the controls. Moreover, phase III inclination angle had significant differences in patients with moderate and severe BA and in those with severe BA. Volumetric capnography parameters - phase III inclination angle and emphysema index - demonstrated the clearest correlation relation with forced expiratory volume during the first spirometric second, as well as with the volumes of the lungs and bronchial resistance index determined by body plethysmography.

Conclusion. Volumetric capnography extends the concept of the nature and degree of the impaired respiratory function in $\mathrm{BA}$, since it enables to assess small airways function and determine the presence and extent of lung hyperinflation. The method enables to undertake a study of pulmonary function in patients with severe bronchial asthma, it being of great importance especially in cases, when spirometry is infeasible.

Study Funding. The work was not supported by any sources.

Conflict of Interests. The authors have no conflict of interests to disclose.

\section{References}

1. Global Initiative for Asthma. Global Strategy for Asthma Management and Prevention (2015 update).

2. Russian Respiratory Society. Federal'nye klinicheskie rekomendatsii po diagnostike i lecheniyu bronkhial'noy astmy [Federal clinical guidelines on diagnosis and treatment of bronchial asthma]. Moscow; 2016.

3. Ferguson G.T., Enright P.L., Buist A.S., Higgins M.W. Office spirometry for lung health assessment in adults: a consensus statement from the National Lung Health Education Program. Chest 2000; 117(4): 1146-1161, https://doi. org/10.1378/chest.117.4.1146.

4. Miller M.R., Hankinson J., Brusasco V., Burgos F., Casaburi R., Coates A., Crapo R., Enright P., van der Grinten C.P., Gustafsson P., Jensen R., Johnson D.C., Maclntyre N., McKay R., Navajas D., Pedersen O.F., Pellegrino R., Viegi G., Wanger J.; ATS/ERS Task Force.
Standardisation of spirometry. Eur Respir J 2005; 26(2): 319338, https://doi.org/10.1183/09031936.05.00034805.

5. Russian Respiratory Society. Federal'nye klinicheskie rekomendatsii po ispol'zovaniyu metoda spirometrii [Federal clinical guidelines on using spirometry]. Moscow; 2013.

6. Funktsional'naya diagnostika v pul'monologii [Functional diagnostics in pulmonology]. Pod red. Chuchalina A.G. [Chuchalin A.G. (editor)]. Moscow: Atmosfera; 2009; 192 p.

7. Solov'eva A.V., Byalovskiy Yu.Yu., Rakita D.R. The change of capnographic and spirometric indices in metabolic syndrome. Rossiyskiy mediko-biologicheskiy vestnik im. akademika I.P. Pavlova 2009; 3: 1-5.

8. Baraldo S., Saetta M., Cosio M.G. Pathophysiology of the small airways. Semin Respir Crit Care Med 2003; 24(5): 465-472.

9. Burgel P.R., Bourdin A., Chanez P., Chabot F., Chaouat A., Chinet T., de Blic J., Devillier P., Deschildre A., Didier A., Garcia G., Jebrak G., Laurent F., Morel H., Perez T., Pilette C., Roche N., Tillie-Leblond I., Verbanck S., Dusser D. Update on the roles of distal airways in COPD. Eur Respir Rev 2011; 20(119): 7-22, https://doi. org/10.1183/09059180.10010610.

10. Contoli M., Bousquet J., Fabbri L.M., Magnussen H., Rabe K.F., Siafakas N.M., Hamid Q., Kraft M. The small airways and distal lung compartment in asthma and COPD: a time for reappraisal. Allergy 2010; 65(2): 141-151, https://doi. org/10.1111/j.1398-9995.2009.02242.x.

11. Nenasheva N.M. Role of small airways in bronchial asthma. Pul'monologiya i allergologiya 2010; 4: 27-33.

12. Saetta M., Di Stefano A., Rosina C., Thiene G., Fabbri L.M. Quantitative structural analysis of peripheral airways and arteries in sudden fatal asthma. Am Rev Respir Dis 1991; 143(1): 138-143, https://doi.org/10.1164/ajrccm/143.1.138.

13. Carroll N., Cooke C., James A. The distribution of eosinophils and lymphocytes in the large and small airways of asthmatics. Eur Respir J 1997; 10(2): 292-300, https://doi.org/ 10.1183/09031936.97.10020292.

14. Booker R. Interpretation and evaluation of pulmonary function tests. Nurs Stand 2009; 23(39): 46-56, https://doi. org/10.7748/ns2009.06.23.39.46.c7040.

15. Byalovskiy Yu.Yu., Abrosimov V.N. Kapnografiya $v$ obshchey vrachebnoy praktike [Capnography in general medical practice]. LAP Lambert Academic Publishing; 2014; 136 p.

16. Suarez-Sipmann F., Bohm S.H., Tusman G. Volumetric 
capnography. Curr Opin Crit Care 2014; 20(3): 333-339, https://doi.org/10.1097/mcc.0000000000000095.

17. Veronez L., Pereira M., Silva S., Barcaui L., Capitani E., Moreira M., Paschoalz I. Volumetric capnography for the evaluation of chronic airways diseases. Int $J$ Chron Obstruct Pulmon Dis 2014; 9(1): 983-989, https://doi.org/10.2147/copd. s62886.

18. Capnography. Gravenstein J.S., Jaffe M.B., Gravenstein N., Paulus D.A. (editors). Cambridge University Press; 2011; 475 p.

19. Almeida C.C., Almeida-Júnior A.A., Ribeiro M.A., Nolasco-Silva M.T., Ribeiro J.D. Volumetric capnography to detect ventilation inhomogeneity in children and adolescents with controlled persistent asthma. J Pediatr 2011; 87(2): 163168, https://doi.org/10.2223/jped.2077.

20. Qi G.-S., Gu W.-C., Yang W.-L., Xi F., Wu H., Liu J.-M. The ability of volumetric capnography to distinguish between chronic obstructive pulmonary disease patients and normal subjects. Lung 2014; 192(5): 661-668, https://doi.org/10.1007/ s00408-014-9615-4.

21. Verschuren F., Liistro G., Coffeng R., Thys F., Roeseler J., Zech F., Reynaert M. Volumetric capnography as a screening test for pulmonary embolism in the emergency department. Chest 2004; 125(3): 841-850, https://doi. org/10.1378/chest.125.3.841.

22. Ponomareva I.B., Subbotin S.V. Possibilities of volumetric capnography method in the study of pulmonary functions in patients with COPD. Nauka molodykh - Eruditio Juvenium 2016; 1: 68-73.

23. Verschuren F., Heinonen E., Clause D., Roeseler J., Thys F., Meert P., Marion E., El Gariani A., Col J., Reynaert M., Liistro G. Volumetric capnography as a bedside monitoring of thrombolysis in major pulmonary embolism. Intensive Care Med 2004; 30(11): 2129-2132, https://doi.org/10.1007/ s00134-004-2444-9.

24. Tusman G., Suarez-Sipmann F., Böhm S.H., Pech T., Reissmann H., Meschino G., Scandurra A., Hedenstierna G. Monitoring dead space during recruitment and PEEP titration in an experimental model. Intensive Care Med 2006; 32(11): 1863-1871, https://doi.org/10.1007/s00134-006-0371-7.

25. Cheifetz I.M., Myers T.R. Respiratory therapies in the critical care setting. Should every mechanically ventilated patient be monitored with capnography from intubation to extubation? Respir Care 2007; 52(4): 423-442.

26. Tusman G., Böhm S.H., Sipmann F.S., Maisch S. Lung recruitment improves the efficiency of ventilation and gas exchange during one-lung ventilation anesthesia. Anesth Analg 2004; 98(6): 1604-1609, https://doi.org/10.1213/01. ane.0000068484.67655.1a.

27. Gustafsson P.M., Ljungberg H.K., Kjellman B. Peripheral airway involvement in asthma assessed by singlebreath SF6and He washout. Eur Respir J 2003; 21(6): 10331039, https://doi.org/10.1183/09031936.03.00049302.

28. Arnold J.H., Stenz R.I., Grenier B., Thompson J.E.
Single-breath $\mathrm{CO}_{2}$ analysis as a predictor of lung volume change in a model of acute lung injury. Crit Care Med 2000; 28(3): 760 764, https://doi.org/10.1097/00003246-200003000-00026.

29. Kline J.A., Israel E.G., Michelson E.A., O'Neil B.J., Plewa M.C., Portelli D.C. Diagnostic accuracy of a bedside D-dimer assay and alveolar dead-space measurement for rapid exclusion of pulmonary embolism. JAMA 2001; 285(6): 761-768, https://doi.org/10.1001/jama.285.6.761.

30. Verschuren F., Heinonen E., Clause D., Roeseler J., Thys F., Meert P., Marion E., El Gariani A., Col J., Reynaert M., Liistro G. Volumetric capnography as a bedside monitoring of thrombolysis in major pulmonary embolism. Intensive Care Med 2004; 30(11): 2129-2132, https://doi.org/10.1007/s00134004-2444-9.

31. Moreira M.M., Terzi R.G., Carvalho C.H., de Oliveira Neto A.F., Pereira M.C., Paschoal I.A. Alveolar dead space and capnographic variables before and after thrombolysis in patients with acute pulmonary embolism. Vasc Health Risk Manag 2008; 5(1): 9-12, https://doi.org/10.2147/vhrm.s4499.

32. Moreira M.M., Terzi R.G., Paschoal I.A., Martins L.C., Oliveira E.P., Falcão A.L. Thrombolysis in massive pulmonary embolism based on the volumetric capnography. Arq Bras Cardiol 2010; 95(4): e97-e99, https://doi.org/10.1590/s0066782x2010001400025.

33. Kallet R.H., Daniel B.M., Garcia O., Matthay M.A. Accuracy of physiologic dead space measurements in patients with acute respiratory distress syndrome using volumetric capnography: comparison with the metabolic monitor method. Respir Care 2005; 50(4): 462-467.

34. Romero P.V., Lucangelo U., Lopez Aguilar J., Fernandez R., Blanch L. Physiologically based indices of volumetric capnography in patients receiving mechanical ventilation. Eur Respir J 1997; 10(6): 1309-1315, https://doi. org/10.1183/09031936.97.10061309.

35. Koulouris N.G., Latsi P., Stavrou E., Chroneou A., Gaga M., Jordanoglou J. Unevenness of ventilation assessed by the expired $\mathrm{CO}_{2}$ gas volume versus $\mathrm{V}(\mathrm{T})$ curve in asthmatic patients. Respir Physiol Neurobiol 2004; 140(3): 293-300, https://doi.org/10.1016/j.resp.2004.01.005.

36. Kars A.H., Goorden G., Stijnen T., Bogaard J.M., Verbraak A.F., Hilvering C. Does phase 2 of the expiratory $\mathrm{PCO}_{2}$ versus volume curve have diagnostic value in emphysema patients? Eur Respir J 1995; 8(1): 86-92, https:// doi.org/10.1183/09031936.95.08010086.

37. Romero P.V., Rodriguez B., de Oliveira D., Blanch L. Manresa F. Volumetric capnography and chronic obstructive pulmonary disease staging. Int J Chron Obstruct Pulmon Dis 2007; 2(3): 381-391.

38. Ribeiro M.Â., Silva M.T., Ribeiro J.D., Moreira M.M., Almeida C.C., Almeida-Junior A.A., Ribeiro A.F., Pereira M.C., Hessel G., Paschoal I.A. Volumetric capnography as a tool to detect early peripheric lung obstruction in cystic fibrosis patients. J Pediatr 2012; 88(6): 509-517, https://doi. org/10.2223/jped.2233. 